\title{
Validation of a measurement procedure for the assessment of the safety of buildings in urgent technical rescue operations
}

\author{
Maria Alicandroํ, Giulio D’Emilia ${ }^{2}$, Donatella Dominici ${ }^{1}$, Antonella Gaspari ${ }^{3}$, Stefano Marsella ${ }^{4}$, \\ Marcello Marzoli ${ }^{4}$, Emanuela Natale ${ }^{2}$, Sara Zollini ${ }^{1}$ \\ ${ }^{1}$ DICEAA, Università dell'Aquila, via G. Gronchi 18, 67100 L'Aquila, Italy \\ 2 DIIIE, Università dell'Aquila, via G. Gronchi 18-67100, L'Aquila, Italy \\ ${ }^{3}$ DMMM, Politecnico di Bari, via Orabona 4, 70125 Bari, Italy \\ ${ }^{4}$ Dipartimento dei Vigili del Fuoco del Soccorso pubblico e della Difesa civile, Ministero dell'Interno, piazzale Viminale 1, 00184 Roma, Italy
}

\section{ABSTRACT}

This work would like to provide a preliminary contribution to the draft of standard procedures for the adoption of Total Stations by rescuers in emergency situations, so as to offer a reliable and effective support to their assessment activities. In particular, some considerations will be made regarding the effect of the number and positioning of monitoring points on the tilt determination of a building façade, in order to set up simplified procedures, which are quick and easy to implement in emergency situations, at the same time guaranteeing the reliability of the results. Two types of building will be taken into account as test cases, which have different characteristics in terms of height, distance and angle with respect to the Total Station. Some considerations will be made about the aspects to be explored in future work, for the calibration of the method as a whole and the definition of all the steps of a procedure for the evaluation of the safety of a building.

\section{Section: RESEARCH PAPER}

Keywords: Validation; measurement uncertainty; calibration; total station; building monitoring; technical rescue

Citation: Maria Alicandro, Giulio D’Emilia, Donatella Dominici, Antonella Gaspari, Stefano Marsella, Marcello Marzoli, Emanuela Natale, Sara Zollini, Validation of a measurement procedure for the assessment of the safety of buildings in urgent technical rescue operations, Acta IMEKO, vol. 10, no. 4, article 23, December 2021, identifier: IMEKO-ACTA-10 (2021)-04-23

Section Editor: Roberto Montanini, Università di Messina and Alfredo Cigada, Politecnico di Milano, Italy

Received July 26, 2021; In final form December 6, 2021; Published December 2021

Copyright: This is an open-access article distributed under the terms of the Creative Commons Attribution 3.0 License, which permits unrestricted use, distribution, and reproduction in any medium, provided the original author and source are credited.

Corresponding author: Emanuela Natale, e-mail: emanuela.natale@univaq.it

\section{INTRODUCTION}

Seismic-damage prevention is one of the main goals of researchers in the management of historical buildings, and several authors have dealt with the appraisal and the inventory of the building's heritage [1]-[7].

A particular application concerns the evaluations required during urgent technical rescue operations.

Besides the primary target to search and rescue survivors, soon after an earthquake most resources are spent to evaluate the level of damages suffered by buildings and infrastructures, both in the immediate aftermaths of the event, to support the logistics of the rescue itself, to assess the level of safety of the rescue operations and the road network, and in the following phases, to implement provisional measures able to secure buildings and, in particular, the cultural heritage [8]-[12].

Such assessment is quite challenging and critical, both from the technical and the logistic point of view, due to the high number of buildings (up to thousands), good part of which could be listed as cultural heritage. Moreover, recent earthquakes were followed by 1-3 months aftershocks with similar intensity, causing a waste of most of the spent effort, which imposed to repeat the assessments anew.

Up to now, in Italy as well as worldwide, this task has been carried out thanks to the expertise of fire fighters or other technicians, who had to assess the residual safety of the buildings on the only basis of a visual inspection. Such assessment is obviously subjective, even if carried out by applying severe operational procedures, which foresee the analysis of the damages against well-defined schemas. 
To improve the efficiency and reduce the subjectivity of such assessments, the authors propose to employ a dedicated survey system designed to support rescue operations and the implementation of provisional measures. Such system is now possible, thanks to the recent availability of dedicated, userfriendly human-machine interfaces, able to hide the complexity of the employed tools, while maintaining the scientific value of the retrieved data. In fact, such user-friendly interfaces make them accessible by untrained first responders, which are employed on the field in the first phases of the rescue operations [8]-[12].

Systems and tools make less subjective the assessment of building residual safety, and, in particular, could decisively improve the following:

- fast execution of accurate surveys of damaged buildings, so as to reduce the exposure risk of rescuers in the first phase of the emergency;

- detailed design of provisional measures;

- quantitative monitoring of building damage evolution over time;

- quantitative monitoring of provisional measures evolution over time, to assess their residual efficacy, in particular following aftershocks.

Available technologies offer several instruments able to reach the aim. e.g., most common methods to monitor and assess cultural heritage building damage are based on satellite systems, photogrammetry, laser scanning, infrared thermography [13][17]. 3D reconstruction techniques of buildings, based on Unmanned Aerial Vehicle (UAV) tilt photography, have the advantages of multi-angle and three-dimensional, but they are very time-consuming and high levels of accuracy are not easy to achieve [18]-[21]. Approaches are proposed, for identifying intact and collapsed buildings via multi-scale morphological profiles with multi-structuring elements from post-earthquake satellite imagery, or using Synthetic Aperture Radar (SAR) techniques; however, these methodologies do not examine in detail the structural characteristics of individual buildings [22]-[24].

Total stations are remote sensing tools, which can be easily used both indoor and outdoor, thanks to the easy installation and real-time output, rain and wind-proof, wide range of operating temperatures and insensitivity to light conditions. As for total stations used without reflective targets, point distance is measured remotely, at safe distance from the target building, so that surveys are completely not-invasive and safe for the operators. As such, they consent to reach a good balance between precision and data quality, easy-to-use, cost, easy to realtime processing. There are studies in the literature that refer to indoor calibration of Total Stations [25].

To obtain reliable outcomes, it is crucial to standardise procedures which take into proper account the constraints imposed by the deployment on the field in emergency situations. In fact, such environment implies numerous operational issues, due to fast-evolving scenarios, with unpredictable intrusions by rescuers and vehicles. In particular:

- the impossibility to measure some target points, especially the lowest, due to the interposition of obstacles (rescuers and rescue vehicles) between instrument and target;

- the need to deploy as fast as possible, and to survey the minimal number of target points, needed to obtain outcomes with sufficient accuracy;
- the possibility of accidental or voluntary movements of the instruments (e.g., when caterpillars have to move in between), for which it is necessary to define stable reference points, in order to correctly acquire series of data carried out from different positions.

In the process of simplifying and speeding up procedures for using instrumentation in specific applications, validation techniques are needed to ensure the reliability of the results [26][29].

In this paper the authors, as a preliminary contribution, will report their considerations regarding the impact on the tilt determination of a building façade, of the number and positioning of reference and monitoring points. This work would like to contribute to the draft of standard procedures for the adoption of Total Stations by rescuers in emergency situations, so as to offer a reliable and effective support to their assessment activities.

Section 2 will describe the instrumentation used for these tests and the lay-out of the site; the position of the measuring points is also discussed and the measuring set-up able to reduce step by step the monitoring points on which data processing is carried out. In Section 3, the results are presented and analysed with reference to procedure simplification purposes. Conclusions and future work will end the paper.

\section{MATERIALS AND METHODS}

The test area is located in Fossa, a small village next to L'Aquila, in central Italy (Figure 1), hits by 2009 earthquake [15]. The area is a square surrounded by three buildings and a tower. Reference targets have been materialised on two buildings, while monitoring points have been located on the other buildings, the "house" and the "tower" in Figure 2.

These buildings have been chosen as test cases for the analyses, as they have different characteristics from the point of view of height, that implies different distance and inclination angle of the highest points with respect to the position of the measurement system, which is more or less halfway between the two buildings.

The SafeR System has been used to perform the measurements. The SafeR System has been designed to estimate and monitoring any critical movements of structures and civil works. The operating modes and functions have been developed to make the system as suitable as possible for the emergency activities of the fire fighters. It is composed by (Figure 3):

- A total station Leica Geosystems (TPS), model TS16 Imaging, tool used extensively in monitoring activities by measuring azimuthal and zenithal angles and distances from the instrumental centre to the measured point with high precision. These measures (Polar

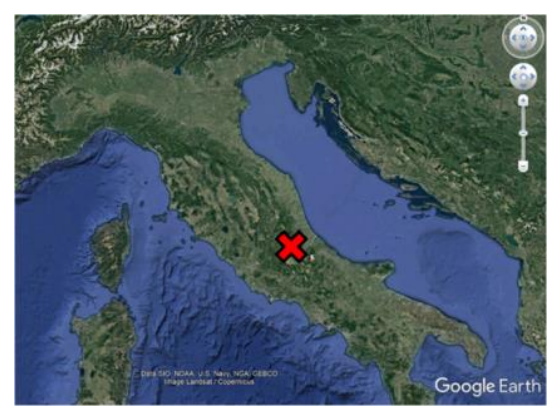

Figure 1. Test area location [Image credit: Google Earth]. 
a)

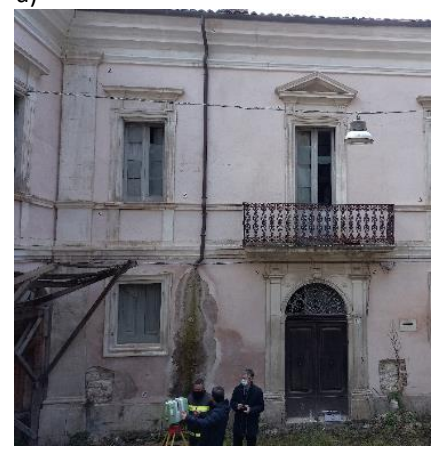

b)

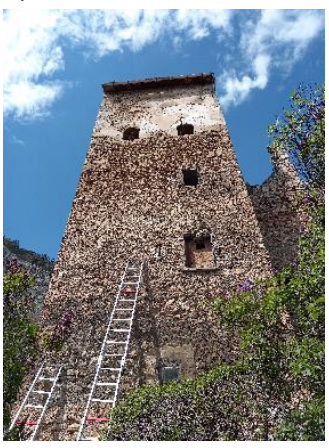

Figure 2. Monitored buildings: a) house; b) tower.

coordinates) are transformed by the system into Cartesian coordinates (X, Y, Z);

- $\quad$ Software SafeR, in order to manage the total station;

- a tablet PC, with the software installed on it, able to communicate with the Leica Total Station (TPS) both by wireless and with dedicated cabling.

By measuring the $3 \mathrm{D}$ coordinates, it is possible to carry out monitoring and control activities of slow or relatively fast movements over time both in external and internal environments, during day and night. All measurements are carried out automatically in order to exclude any errors by the operators. The measurement results are immediately processed in the field and displayed in graphical and tabular form, helping the operator to fast interpretate the phenomenon in progress and make immediate decisions.

The SafeR System is designed to provide spatial information (3D coordinates) of punctual points and the operational scene is schematised in Figure 4.

The points on the building considered to be stable are called reference points while the ones on the building to be monitored are called monitoring points. The SafeR System is positioned at the centre in order to have maximum visibility.

All the preliminary operations, required by the standard procedures for using this kind of equipment (fixing the tripod to the ground, levelling), have been correctly carried out.

The measurement by the total station can be carried out in two different ways, by using:

- infrared ray

- laser beam.

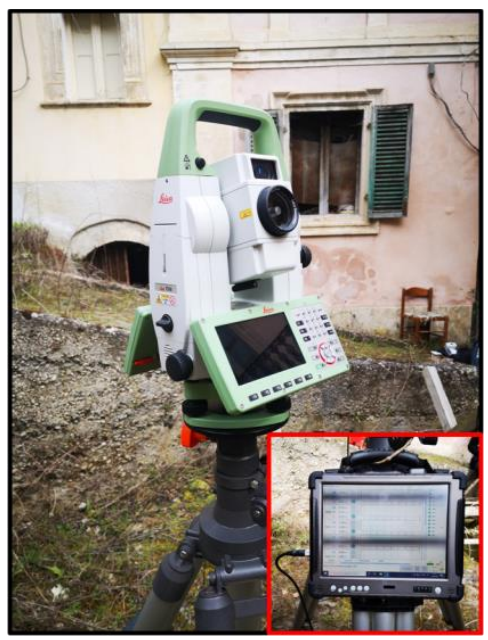

Figure 3. SafeR System used for the analysis.

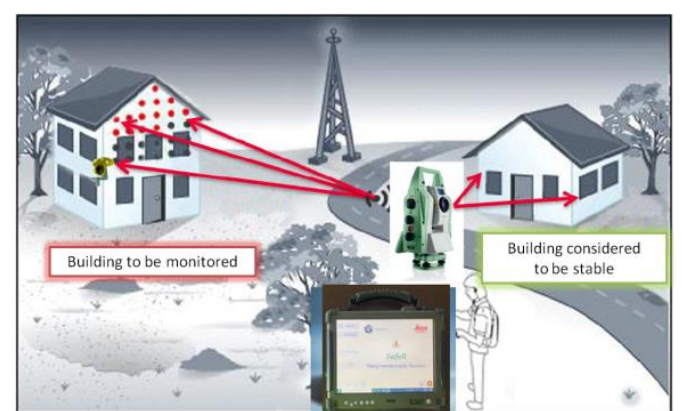

Figure 4. SafeR System operational scene [30].

Surveying by infrared ray needs a reflective target, the prism. Using the prism allows more accurate measurements and guarantees the achievement of greater distances.

The survey by laser beam is adopted to detect points that are difficult to access by the operator, who must physically place the prisms. In this case, in fact, it is not necessary to adopt any external reflecting system.

Reference points have to be defined to have a stable reference, and they must be fixed according to an optimal geometry (not too close or aligned) and on fixed points, not susceptible to movement: these aspects will be taken into account in the procedure definition.

Seven reference points have been placed in independent positions with respect to the monitored buildings.

At the reference points, prisms are used; at the monitoring points, white/black targets (Figure 5) are positioned using epoxy resins, to have reference positions, easily identifiable, on which to impose, in perspective, known displacements for the evaluation of the metrological characteristics of the instrument and to obtain useful information for the optimization of the procedure. The latter targets have reflectivity characteristics similar to those of a common building wall.

A coordinate system has been defined with reference to the first building, the house, in such a way that the $\mathrm{x}$-axis direction is obtained by projecting on the horizontal plane the points taken on the façade, the $z$-axis is vertical and its origin is on the horizontal plane at the height of the instrument, the $y$-axis enters the wall of the house. Figure 6 shows the point clouds acquired on the façades of the two buildings and the defined reference systems.

For each monitoring point, 20 repeated measurements have been carried out. The monitoring points have been named as indicated in Figure 7.

On the basis of the acquired measurements, after elimination of outliers, the following analysis are carried out, using the Matlab software: a)

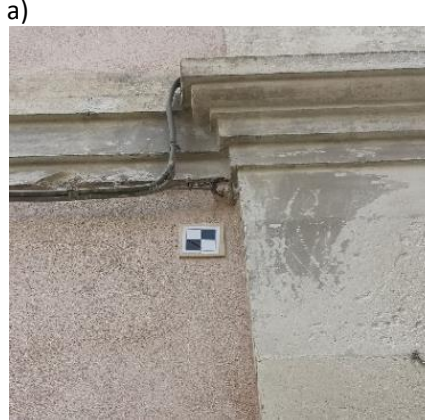

b)

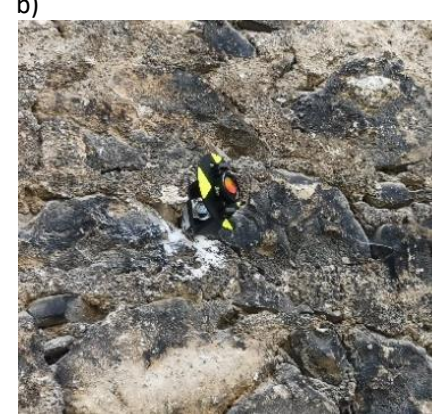

Figure 5. Targets used for monitoring and reference points, respectively: a) black/white target; b) prism. 


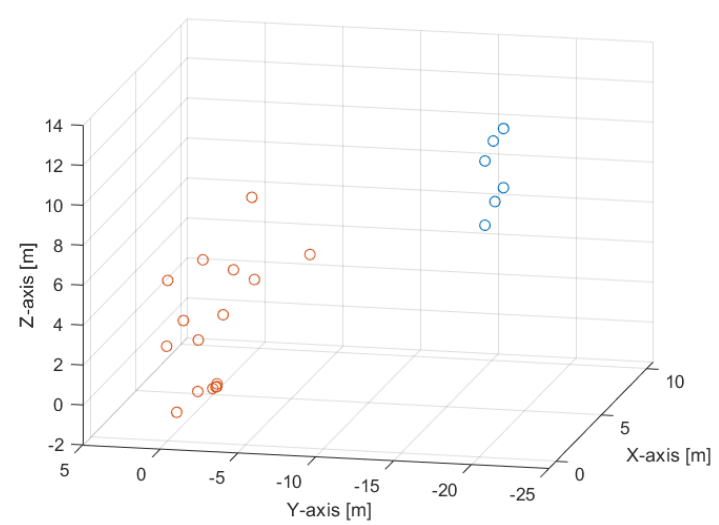

Figure 6. Point clouds acquired on the façades of the buildings: in red the points on the house; in blue the points on the tower.

1. Standard deviations of the measured values of the coordinates of the monitoring points are calculated, on the basis of 20 repeated measurements.

2. The selected points (ML 1-12 for the house, ML 14-19, for the tower) are processed by means of a least squares regression (first degree polynomial model) and the inclination angles of the façades are determined with respect to the horizontal plane. These values are considered as a reference, with respect to which to evaluate other configurations of the monitoring points.

3. The angle of inclination is calculated with reference to the configurations described in Figure 8 and Figure 9, that is:

- excluding points along vertical lines from the analysis (configurations b, c, d and e for house; configurations b' and c' for tower)

- excluding the points along the lowest line, only in the case of house (configuration $\mathrm{f}$ )

- considering only extreme points (configuration $\mathrm{g}$ and $\mathrm{h}$ for house; configuration d' for tower).

\section{RESULTS}

Figure 10 and Figure 11 show the calculated standard deviations for the monitoring points on the house and the tower: these values do not exceed $5 \mathrm{~mm}$.

The selected points (ML 1-12 for the house, ML 14-19, for the tower) are processed by means of a least squares regression, according to a first degree polynomial model, and the inclination angles of the façades are determined with respect to the horizontal plane.

a)

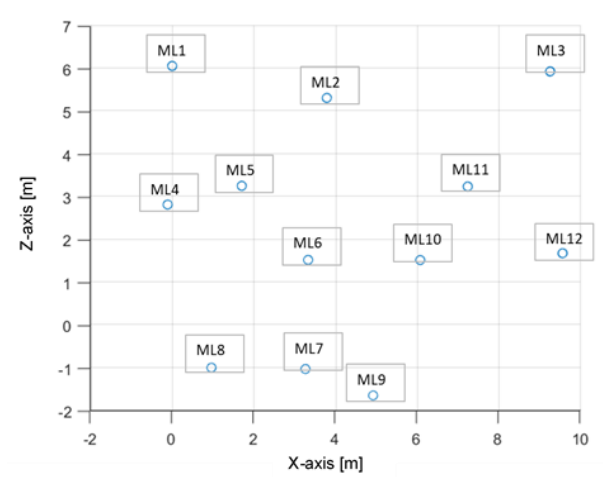

Table 1. Results of the least squares regression.

\begin{tabular}{lcc}
\hline & House & Tower \\
\hline Inclination angle & $89.99^{\circ}$ & $89.93^{\circ}$ \\
Signs of $\cos \left(r_{\mathrm{y}}\right)$ and $\cos \left(r_{\mathrm{z}}\right)$ & concordant & concordant \\
\hline
\end{tabular}

The obtained results, in terms of inclination angles and signs of the direction cosines $\left(\cos \left(r_{\mathrm{y}}\right)\right.$ and $\left.\cos \left(r_{\mathrm{z}}\right)\right)$ of the normal to the plane, are summarized in Table 1 . The sign of the direction cosines indicates if the façade is inclined towards the outside or inside of the building: taking into account Figure 6, in the case of the house, if the signs of $\cos \left(r_{\mathrm{z}}\right)$ and $\cos \left(r_{\mathrm{y}}\right)$ are concordant, the façade is inclined toward the outside, if discordant toward the inside; in the case of tower, on the contrary, if the signs are concordant, the façade is inclined toward the inside.

The least squares regression has been also performed for the configurations of Figure 8 and Figure 9, and the inclination differences with respect to the reference case have been calculated (Figure 12 and Figure 13).

Furthermore, the displacement in the horizontal direction of the highest point in both the two buildings has been evaluated (Figure 14 and Figure 15). The following observations can be made:

- For the house, variations in the angle of inclination up to $0.18^{\circ}$, compared to the reference case, may result, by changing the number of points chosen for processing; the displacements evaluated in the horizontal direction, at the height of the highest point, can reach about $20 \mathrm{~mm}$.

- For the tower, variations in the angle of inclination up to $0.062^{\circ}$, compared to the reference case, may result, by changing the number of points chosen for processing; the displacements evaluated in the horizontal direction, at the height of the highest point, can reach about 25 $\mathrm{mm}$.

- The results show, for both buildings, that the acquisition of only the extreme monitoring points allows to obtain results comparable to those of the reference case. These results appear promising from the point of view of the possibility of simplification, also considering that the standard deviation of the measurements is lower with respect to the calculated displacements.

- It must be noticed that the standard deviation of the measurements is greater in some areas of the façade of the house, and this does not seem to be directly related to parameters such as distance and angle of positioning of the total station with respect to the building. This aspect will need to be explored in future work.

b)

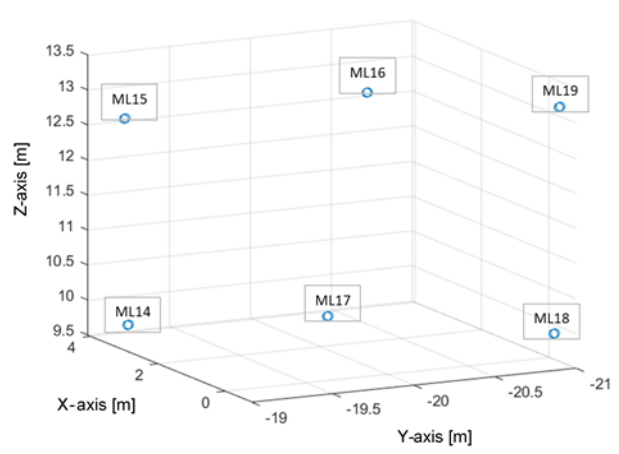

Figure 7. Identification codes of the monitoring points for: a) house; b) tower. 
a)
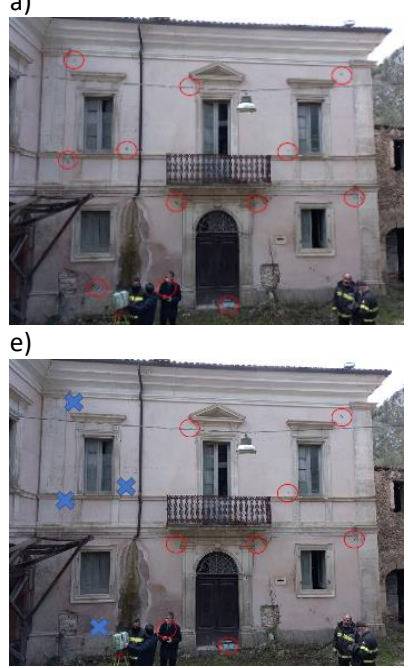
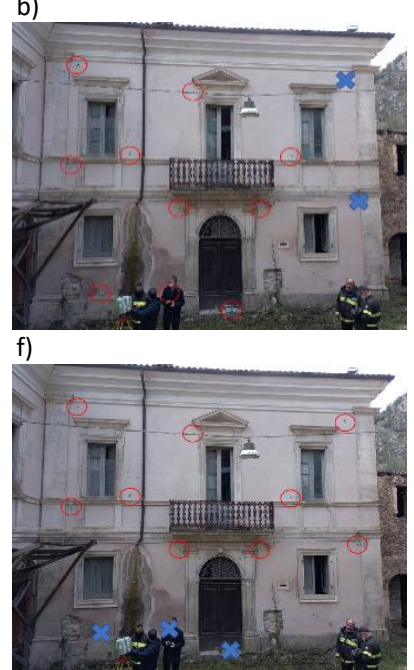
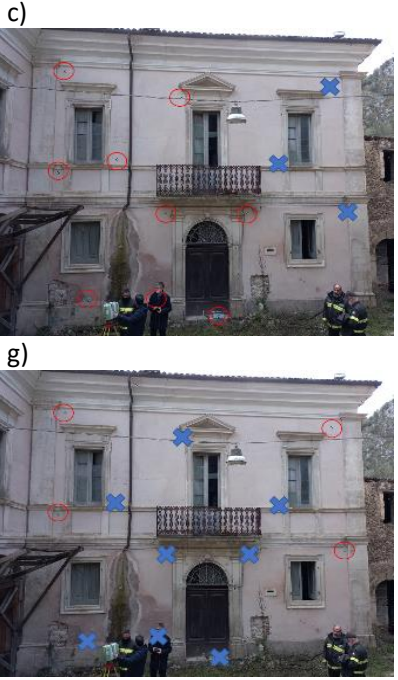
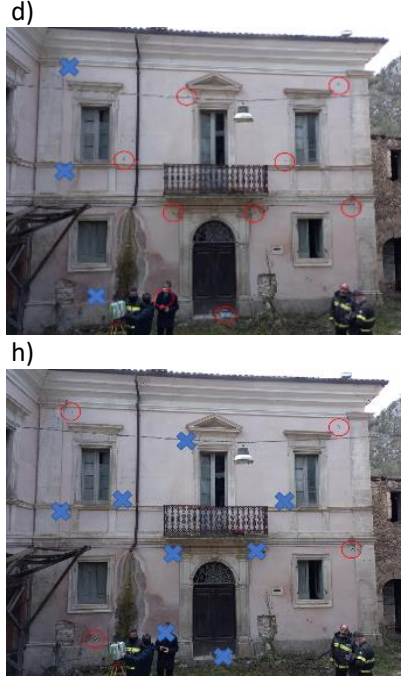

Figure 8. Configurations of measuring point for the house: a) "Ref" (reference); b) "Config 2"; c) "Config 3"; d) "Config 4"; e) "Config 5"; f) "Config 6"; g) "Config 7"; h) “Config 8".

a)

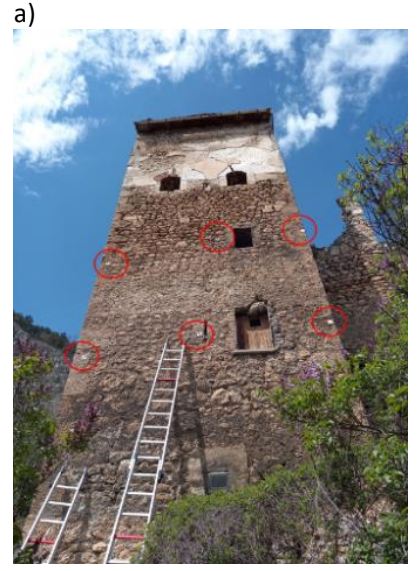

b)

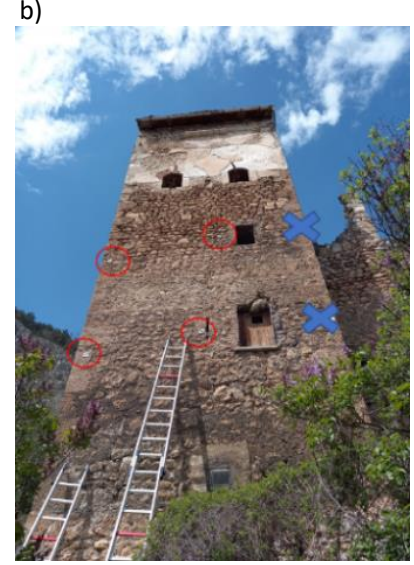

c)

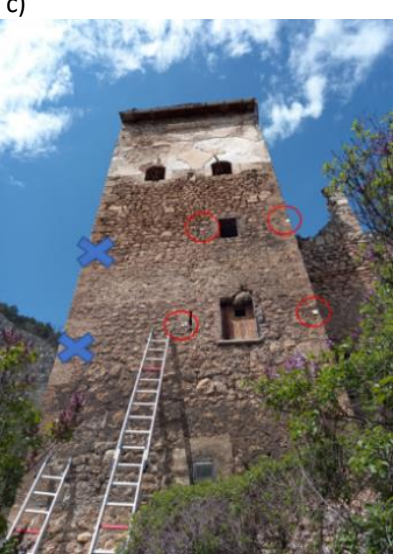

d)

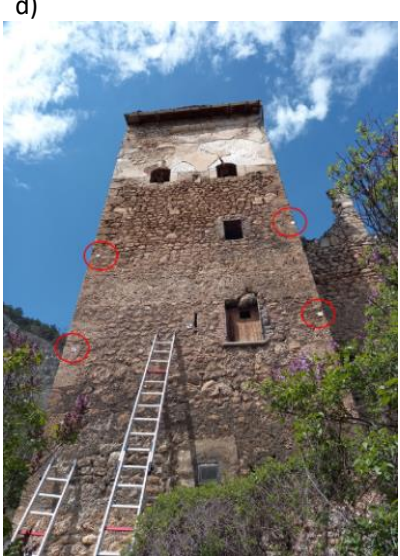

Figure 9. Configurations of measuring point for the tower: a') “Ref” (reference); b') “Config 2'”; c') “Config 3'”; d') “Config 4'”.

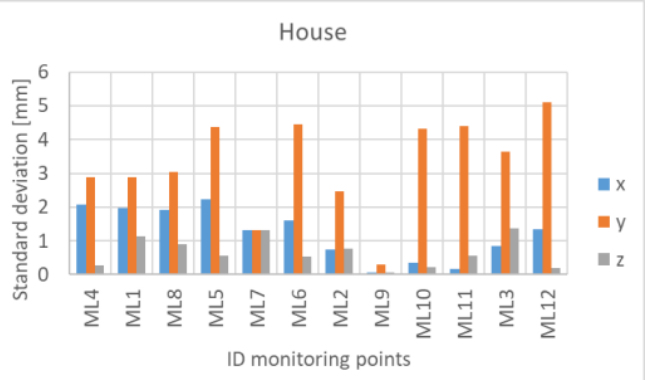

Figure 10. Standard deviation of the coordinates of the monitoring points for the house.

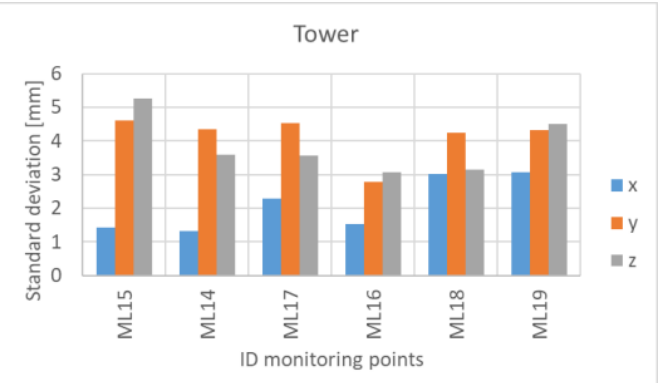

Figure 11. Standard deviation of the coordinates of the monitoring points for the tower.

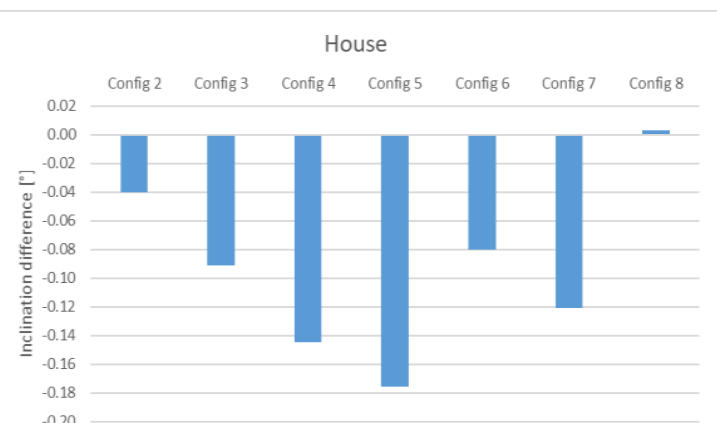

Figure 12. Inclination difference with respect to the reference for the house.

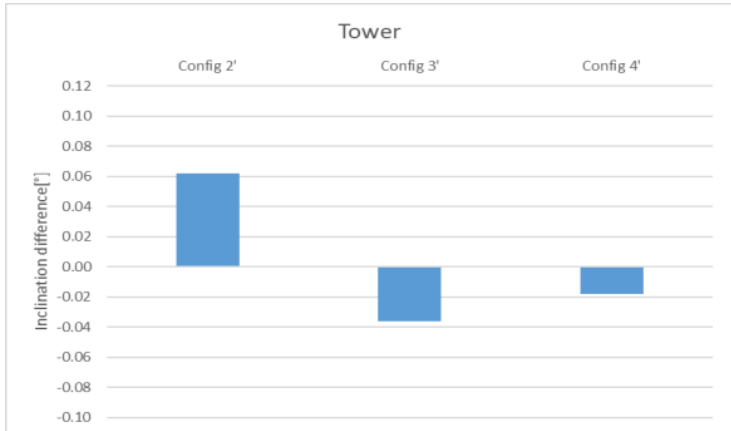

Figure 13. Inclination difference with respect to the reference for the tower. 
House

Horizontal displacement of the higher point $(z=6.1 \mathrm{~m})$

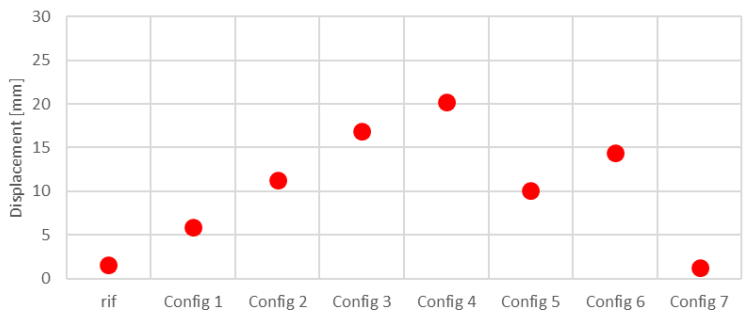

Figure 14. Horizontal displacement of the higher point for the house.

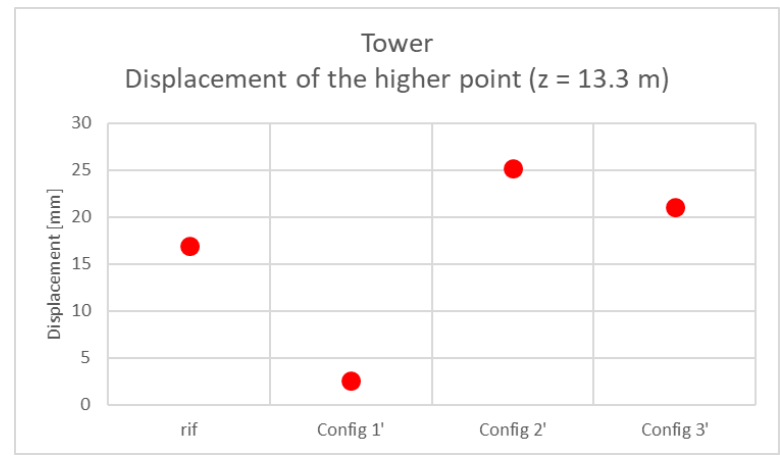

Figure 15. Horizontal displacement of the higher point for the tower.

\section{CONCLUSIONS}

In this paper some considerations have been made regarding the effect on the tilt determination of a building façade of the number and positioning of the monitoring points. The study has been conducted considering two buildings with different characteristics as test cases.

The results show, for both buildings, that the acquisition of only part of the monitoring points can allow to obtain results comparable to those of the reference case. These results appear promising from the point of view of the possibility of simplification, also considering that the standard deviation of the measurements do not exceed $5 \mathrm{~mm}$, and it is lower than the calculated displacements $(20 \mathrm{~mm}-25 \mathrm{~mm})$.

In future work monitoring targets will be subject to known displacements to calibrate the method on the whole. Furthermore, the causes of increased standard deviation of the measurements carried out in specific areas will be investigated.

\section{ACKNOWLEDGMENTS}

Work carried out with the co-financing of the STORM research and development project, funded by the European Commission for the Horizon 2020 Program.

Thanks are due to Angelo Celano and Luca Macerola, of Leica Geosystems S.p.A., for the technical support.

\section{REFERENCES}

[1] R. S. Olivito, S. Porzio, C. Scuro, D. L.Carnì, F. Lamonaca, Inventory and monitoring of historical cultural heritage buildings on a territorial scale: a preliminary study of structural health monitoring based on the CARTIS approach, Acta IMEKO, 10 (2021) 1, pp. 57-69.

DOI: $10.21014 /$ acta imeko.v10i1.820
[2] V. Sangiorgio, Martiradonna, F. Fatiguso, G. Uva, Historical masonry churches diagnosis supported by an analytic-hierarchyprocess-based decision support system, Acta IMEKO, 10 (2021) 1, pp. 6-14.

DOI: $10.21014 /$ acta imeko.v10i1.793

[3] R. Spallone, G. Bertola, F. Ronco, Digital strategies for the valorisation of archival heritage, Acta IMEKO, 10 (2021) 1, pp. 224-233.

DOI: $10.21014 /$ acta imeko.v10i1.883

[4] V. Croce, G. Caroti, A. Piemonte, M.G. Bevilacqua, From survey to semantic representation for Cultural Heritage: the 3D modeling of recurring architectural elements, Acta IMEKO, 10 (2021) 1, pp. 98-108.

DOI: $10.21014 /$ acta imeko.v10i1.842

[5] I. Roselli, A. Tatì, V. Fioriti, I. Bellagamba, M. Mongelli, R. Romano, G. De Canio, M. Barbera, M. M. Cianetti, Integrated approach to structural diagnosis by non-destructive techniques: the case of the Temple of Minerva Medica, Acta IMEKO, 7 (2018) 3, pp. 13-19.

DOI: $10.21014 /$ acta imeko.v7i3.558

[6] A. Malagnino, G. Mangialardi, G. Zavarise, A. Corallo, Process modeling for historical buildings restoration: An innovation in the management of cultural heritage, Acta IMEKO, 7 (2018) 3, pp. 95-103.

DOI: $10.21014 /$ acta imeko.v7i3.602

[7] F. Lamonaca, C. Scuro, P.F. Sciammarella, R.S. Olivito, D. Grimaldi, D.L. Carnì, A layered IoT-based architecture for a distributed structural health monitoring system, Acta IMEKO, 8 (2019) 2, pp. 45-52.

DOI: $10.21014 /$ acta imeko.v8i2.640

[8] Y. Hashem, J. Ambani, A story of Change. Published by the International Centre for the Study of the Preservation and Restoration of Cultural Property (ICCROM), Rome, Italy, 2021.

[9] S. Marsella, M. Marzoli, L'uso di tecnologie innovative nella valutazione speditiva del rischio, Convegno Internazionale di Studi "Monitoraggio e manutenzione nelle aree archeologiche. Cambiamenti climatici, dissesto idrogeologico, degrado chimicoambientale", L'Erma di Bretschneider, Bibliotheca Archaeologica, 2020, pp. 165-170, ISBN: 9788891322029.

[10] A. Utkin, L. Argyriou, V. Bexiga, F. Boldrighini, G. Cantoro, P. Chaves, F. Cakır, Advanced Sensing and Information Technologies for Timely Artefact Diagnosis, Pisa University Press, 2019, ISBN 978-88-3339-240-0.

[11] Methodologies for Quick Assessment of Building Stability in the EU STORM Project (2018, September). Proceedings of the XXI International NKF Conference, Reykjavík, Iceland.

[12] S. Marsella, M. Marzoli, L. Palestini, Results of H2020 STORM project in the assessment of damage to cultural heritage buildings following seismic events, (2020).

[13] S. Zollini, M. Alicandro, D. Dominici, R. Quaresima, M. Giallonardo, UAV Photogrammetry for Concrete Bridge Inspection Using Object-Based Image Analysis (OBIA), Remote Sens., 12 (2020) 3180. DOI: $10.13140 / R G \cdot 2.2 .35754 .85441$ 04/07/2020

[14] D. Dominici, E. Rosciano, M. Alicandro, M. Elaiopoulos, S. Trigliozzi, V. Massimi, Cultural heritage documentation using geomatic techniques: Case study: San Basilio's monastery, L'Aquila. In 2013 Digital Heritage International Congress (DigitalHeritage) 1, (2013) pp. 211-214. DOI: 10.1109/DigitalHeritage.2013.6743735

[15] Dominici, D., Galeota, D., Gregori, A., Rosciano, E., Alicandro, M. Elaiopoulos, Integrating geomatics and structural investigation in post-earthquake monitoring of ancient monumental Buildings, J. Appl. Geod., 8 (2014), pp. 141-154. DOI: $10.1515 /$ jag-2012-0008

[16] F. Yang, X. Wen, X. Wang, X. Li, Z. Li, A Model Study of Building Seismic Damage Information Extraction and Analysis on Ground-Based LiDAR Data, Adv. Civ. Eng., 2021 (2021), 5542012 . DOI: $\underline{10.1155 / 2021 / 5542012}$ 
[17] I. M. E. Zaragoza, G. Caroti, A. Piemonte, The use of image and laser scanner survey archives for cultural heritage 3D modelling and change analysis, Acta IMEKO, 10 (2021) 1, pp. 114-121. DOI: $10.21014 /$ acta imeko.v10i1.847

[18] X. Chen, J. Lin, X. Zhao, S. Xiao, Research on UAV Oblique Photography Route planning in the investigation of building damage after the earthquake, IOP Conference Series: Earth and Environmental Science, 783 (2021), 012081.

DOI: $10.1088 / 1755-1315 / 783 / 1 / 012081$

[19] R. Zhan, H. Li, K. Duan, S. You, K. Liu, F. Wang, Y. Hu, Automatic detection of earthquake-damaged buildings by integrating UAV oblique photography and infrared thermal imaging, Remote Sens., 12 (2020), 2621. DOI: $10.3390 / \mathrm{rs} 12162621$

[20] M.G. D’Urso, V. Manzari, S. Lucidi, F. Cuzzocrea, Rescue Management and assessment of structural Damage by UAV in post-seismic, ISPRS Ann. Photogramm. Remote Sens. Spat. Inf. Sci., 5 (2020), pp. 61 - 703. DOI: $10.5194 /$ isprs-annals-V-5-2020-61-2020

[21] C.C. Chuang, J. Y. Rau, M.K. Lai, C.L. Shi, Combining Unmanned Aerial Vehicles, and Internet Protocol Cameras to Reconstruct 3 D Disaster Scenes During Rescue Operations, Prehosp. Emerg. Care, 23 (2019), pp. 479-4844.

DOI: $10.1080 / 10903127.2018 .1528323$

[22] R. Zhang, K. Duan, S. You, F. Wang, S. Tan, A novel remote sensing detection method for buildings damaged by earthquake based on multiscale adaptive multiple feature fusion, Geomat. Nat. Hazards Risk, 11 (2020), pp. 1912-19381. DOI: $10.1080 / 19475705.2020 .1818637$

[23] B. Wang, X. Tan, D. Song, L. Zhang, Rapid Identification of PostEarthquake Collapsed Buildings via Multi-Scale Morphological Profiles with Multi-Structuring Elements, IEEE Access, 8 (2020), pp. $122036-1220562020$.
DOI: 10.1109 /ACCESS.2020.3007255

[24] X. Xiao, W. Zhai, Z. Liu, Building damage information extraction from fully polarimetric SAR images based on variogram texture features, ACRS 2020 - 41st Asian Conference on Remote Sensing2020 41st Asian Conference on Remote Sensing, ACRS 2020, 9 - 11 November 2020.

DOI: $10.5194 /$ isprs-archives-XLIII-B1-2020-587-2020

[25] L. Siaudinyte, Modelling of linear test bench for short distance measurements. Acta IMEKO, 4 (2015) 2, pp. 68-71. DOI: $10.21014 /$ acta imeko.v4i2.229

[26] G. D’Emilia, S. Lucci, E. Natale, F. Pizzicannella, Validation of a method for composition measurement of a non-standard liquid fuel for Emission Factor evaluation, Measurement, 44 (2011), pp. 18-23.

DOI: $10.1016 /$ i.measurement.2010.08.016

[27] G. D'Emilia, A. Gaspari, E. Natale, How simplifying a condition monitoring procedure affects its performances. In 2021 IEEE International Instrumentation and Measurement Technology Conference (I2MTC) (2021), pp. 1-5. IEEE. DOI: $10.1109 /$ I2MTC50364.2021.9459924

[28] G. D'Emilia, D. Di Gasbarro, A. Gaspari, E. Natale, Managing the uncertainty of conformity assessment in environmental testing by machine learning. Measurement, 124 (2018) pp. 560-567. DOI: 10.1016/J.MEASUREMENT.2017.12.034

[29] G. D'Emilia, A. Gaspari, E. Natale, Dynamic calibration uncertainty of three-axis low frequency accelerometers, Acta IMEKO, 4 (2015) 4, pp. 75-81. DOI: $10.21014 /$ acta imeko.v4i4.239

[30] Leica Geosystems AG - Part of Hexagon. Online [Accessed 14 December 2021] https://leica-geosystems.com/ 